district, in order to build human resources in this field. Patients and carers who participated in the REMEDY project were trained to support peers and to facilitate self-help groups. This experience resulted in an observable improvement in patients' overall quality of life. Although on a small scale, it shows the potential Egypt has to enhance its mental health services, to reach out to patients in small villages, and to compensate for the shortage of professionals.

In 2009, Egypt's civil society set up the Egyptian Society for the Protection of the Rights of Mental Patients. Currently, through collaboration between different Egyptian non-governmental organisations that work in the fields of psychosocial rehabilitation and mental disability under the umbrella of mental health users' rights and dignity, a plan is proposed, and has been agreed by involved specialists, experts, users and stakeholders, to set up the first social enterprise in Egypt operated by users, with the aim of promoting social inclusion.

These collaborative efforts in upgrading services and involving informal services, health and psychosocial workers as well as users and families have had a positive impact on reducing the mental health gap, reducing the pressure on mental health hospitals and on retaining psychiatrists, while respecting their basic right to mobility and ensuring exchange of expertise.

\section{References}

Clot, A. B. (1840) Aperçu général sur l'Egypte. Fortin, Masson et cie.

Farid, S. \& El-Batrawy, R. (eds) (2015) Egypt-HIMS: Egypt Household International Migration Survey 2013. Main Findings and Key Indicators. Central Agency for Public Mobilization and Statistics, Arab Republic of Egypt.

Gureje, O., Hollins, S., Botbol, M., et al (2009) Report of the WPA Task Force on Brain Drain. World Psychiatry, 8, 115-118.

Jenkins, R., Kydd, R., Mullen, P., et al (2010) International migration of doctors, and its impact on availability of psychiatrists in low income countries. PLOS One, 5(2), e9049. doi: http://dx.plos. org/10.1371/journal.pone.0009049.

Kakuma, R., Minas, H., van Ginneken, N., et al (2011) Human resources for mental health care: current situation and strategies for action. Lancet, 378, 1654-1663.

Loza, N. \& El Nawawi, M. (2012) Mental health legislation in Egypt. International Psychiatry, 9, 64-66.

Patel, V. (2003) Brain drain and the third world: possible solutions to an intractable problem. BMJ, 327, 926.

Patel, V., Minas, H., Cohen, A., et al (2014) Global Mental Health: Principles and Practice. Oxford University Press.

Sorour, E., Materia, E., Khoweiled, A., et al (2014) Prioritizing psychosocial rehabilitation and users' rights: the community mental health approach in Egypt. International Journal of Human Development and International Cooperation, 4(1), 1-11. Available at http://www.universitasforum.org (accessed December 2014).

World Health Organization (2014) Mental Health Atlas. WHO.

THEMATIC PAPER

1 Senior Lecturer, Department of Psychiatry, University of Ibadan Nigeria, email bibideji@yahoo. com

2Professor of Psychiatry, Department of Psychiatry, University of Ibadan, Nigeria

\title{
Brain drain: a challenge to global mental health
}

\author{
Bibilola D. Oladeji ${ }^{1}$ and Oye Gureje²
}

The brain drain of medical professionals from lower-income to higher-income countries contributes to the current inequity that characterises access to mental healthcare by those in need across the world and hinders efforts to scale up mental health services in resource-constrained settings, especially in Nigeria and other West African countries. The migration of skilled workers is driven by a combination of the globalisation of the labour market and the ability of highly resourced countries to attract and retain specialists from poorer countries. If we are to ameliorate the worldwide shortage of mental health professionals, we need to find innovative ways of attracting young doctors into psychiatric training in all countries. We must also introduce measures to improve health worker retention in low- and middle-income countries.

\section{Background}

The challenge to global public health posed by the migration ('brain drain') of health workers from low- and middle-income countries (LMICs) to highincome countries has been recognised for decades. Despite measures taken by some countries to stem the flow, and attempts to reach international agreements, the migration of health workers has accelerated significantly in recent years, fuelled by a combination of global shortages in the health workforce, population changes in higher-income countries and the globalisation of the labour market for healthcare professionals, allowing them to seek better conditions of service away from their home countries (World Health Organization, 2006; Aluttis et al, 2014). This has greatly exacerbated the global disparities in health workforce distribution. For example, North America bears $10 \%$ of the global burden of disease, but possesses 
$42 \%$ of the world's health workforce. Africa, which bears $25 \%$ of the global burden of disease, has only $3 \%$ of the world's health workforce (World Health Organization, 2006). Global disparities in the distribution of the health workforce have a major impact on mental healthcare delivery because clinical demands require personal expertise and training, rather than advanced technology or equipment.

\section{The magnitude of the problem}

The number of healthcare professionals migrating into the four major destination countries (the UK, the USA, Canada and Australia) has increased over the past decade (Siyam \& Poz, 2014). International medical graduates make up between $27 \%$ and $33 \%$ of physicians in Australia, Canada, the USA and the UK. More than half of these are from LMICs, which are already facing severe shortages of health workers (World Health Organization, 2006; Siyam \& Poz, 2014). Some destination countries, including the UK, engage proactively in the recruitment of health workers from LMICs (Blacklock et al, 2012). The UK has made efforts to recruit from India, South Africa and Pakistan and has also launched an International Fellowship Scheme targeted at particular shortage specialties, including psychiatrists and radiologists (Siyam \& Poz, 2014). Within the six medical specialties targeted by the Fellowship Scheme, 124 of the 202 appointments were made to psychiatric posts (Goldberg, 2004).

In a study based on the American Medical Association's master file for 2011, there were 17376 physicians identified as originating from Africa, of whom $68 \%$ had trained in medical schools in Africa. More than two-thirds of those physicians were trained in schools located in Nigeria or South

\section{Table 1}

Median number of psychiatrists per 100000 population

\begin{tabular}{|l|c|c|c|c|}
\hline & 2001 & 2005 & 2011 & 2014 \\
\hline Low-income countries & 0.06 & 0.05 & 0.05 & 0.1 \\
\hline Lower middle-income countries & 0.9 & 1.05 & 0.54 & 0.4 \\
\hline Higher middle-income countries & 2.4 & 2.70 & 2.03 & 1.2 \\
\hline High-income countries & 9.0 & 10.5 & 8.59 & 6.6 \\
\hline World & 1.0 & 1.20 & $1.27^{\mathrm{a}}$ & $0.9^{\mathrm{a}}$ \\
\hline
\end{tabular}

a The slight drop may reflect underreporting in the 2014 survey of psychiatrists working in private practice, which was given emphasis in the 2011 survey.

Source: Data taken from the respective editions of the World Health Organization's Mental Health Atlas.

\section{Table 2}

Median number of all professionals working in mental health ${ }^{a}$ per 100000 population

\begin{tabular}{|l|r|r|}
\hline & 2011 & 2014 \\
\hline Low-income countries & 1.3 & 0.9 \\
\hline Lower middle-income countries & 10.1 & 3.2 \\
\hline Higher middle-income countries & 29.1 & 15.9 \\
\hline High-income countries & 50.8 & 52.3 \\
\hline World & 10.7 & 9.0 \\
\hline
\end{tabular}

aMental health workers include: psychiatrists, other doctors, psychologists, nurses, social workers, occupational therapists and other professions allied to mental health.

Source: Data taken from the respective editions of the World Health Organization's Mental Health Atlas.
Africa (Tankwanchi et al, 2013). The number of sub-Saharan African physicians registered in the USA increased by over 38\% between 2002 and 2011. Over $50 \%$ of this increase was accounted for by $\mathrm{Ni}$ gerian-trained medical graduates. Proportionate to the size of the physician workforce practising in the source countries, the greatest migrations were from Liberia, Ghana and Ethiopia; they lost $52.3 \%$, $26.2 \%$ and $22.7 \%$ of their physicians respectively (Tankwanchi et al, 2013).

One of the few studies to have examined the international migration of psychiatrists (Jenkins et al, 2010) found that a large proportion of psychiatrists registered to practise in high-income countries were from LMICs. For some of these LMICs (e.g. the Philippines, Bangladesh, India, Liberia, Ghana and Nigeria) the impact has been severe; the number of psychiatrists working in the USA alone outnumbers the number currently practising in their home countries (Jenkins et al, 2010). If they all returned to their original countries to continue their psychiatric careers, there would be between two and eight times more psychiatrists per 100000 population (Jenkins et al, 2010).

While the ratio of professionals in the mental health workforce to the size of the general population continues to improve in high-income countries, the same cannot be said for LMICs (see Tables 1 and 2). In the UK, the ratio of psychiatrists to the population served increased from 5.9/100000 in 2003 to $7.6 / 100000$ in 2013. On the other hand, in Africa the equivalent ratio remained extremely low, just $0.1 / 100000$ in 2014. Based on data from the World Health Organization's 2011 Mental Health Atlas, Kakuma et al (2011) estimated that an additional 1.18 million mental health workers are needed in LMICs to deliver basic mental health interventions.

In the West African sub-region, only Ghana and Nigeria have accredited training programmes for resident doctors in psychiatry who are registered with the West African College of Physicians and equivalent colleges. Most of the other countries in West Africa lack the staff to train psychiatrists. Nigeria's postgraduate training programme in psychiatry dates back over 30 years, yet there are few accredited training institutions with the capacity to train psychiatrists and currently only about 250 psychiatrists are practising in Nigeria, a country with a population of over 175 million. It is instructive to contrast this situation with the USA, which has a population of 324 million and 50000 psychiatrists. In most of Nigeria, psychiatrists work in tertiary healthcare centres (university teaching hospitals and stand-alone neuropsychiatric hospitals) that are located in major urban centres. Despite the fact that only a few specialists are being trained within the country, many still have difficulties finding jobs after training, a situation that encourages emigration to other countries, mostly to Western Europe and North America.

Migration of healthcare workers puts more strain on the already overstretched health systems of the source countries, and results in a loss of 
the source country's investment in professional training. Mills et al (2011) estimated that nine source countries in sub-Saharan Africa had lost more than US $\$ 2$ billion from training doctors who then migrated to one of the four major destination countries (again, the USA, the UK, Australia and Canada). The cost to the LMIC of a higher-income country recruiting a locally trained psychiatrist includes at least 11 years of investment in professional training, the value of specialist provision of clinical services, the loss to the host country of that individual's potential role in service development and teaching, as well as the cost of finding a replacement specialist (Ndetei et al, 2004). It is arguable that this cost should be reimbursed by the country hosting the migrant professional, through investment in the source country's training schemes and by other means (Mills et al, 2011).

\section{Recent developments}

The migration of health workers from poorly resourced to rich countries has sparked ethical debates. These centre on the rights of the individual health workers to seek better working and living conditions, the right of the citizens of source countries (who financed the training of the health workers) to equitable access to healthcare, and the undue advantage possessed by wealthy nations in attracting and retaining highly skilled health professionals in a globalised economy. There have been calls for the development of national policies and international guidelines to regulate the international recruitment of health workers, resulting in the World Health Organization's Global Code of Practice on the International Recruitment of Health Personnel, which was adopted by the 63rd World Health Assembly in May 2010 (see also Siyam \& Poz, 2014). The Code aims to

'encourage the development of human resources for health through all aspects of education, improved retention and fair recruitment practices while encouraging technical collaboration and financial support.'

It proposes that the conditions for international recruitment of health personnel be set out in bilateral agreements between source and destination countries, but this proposal has not been widely followed because its implementation is voluntary. Some destination countries are apparently unaware of the Code's requirements, and health workforce flows are not reported by most source countries.

Some source countries have now put in place policies to reduce the emigration of doctors. There was a reduction in the registration of doctors in the UK who had trained in South Africa, from 3206 in 2003 to just 4 in 2004, following a memorandum of understanding signed between the two countries in 2003 (Blacklock et al, 2012). On the other hand, by 2010 South Africa had become the biggest source country for doctors registering with the Medical Council of Ireland (Bidwell et al, 2013) where no such memorandum of understanding existed. Meanwhile, South Africa has banned the recruitment of doctors from other sub-Saharan African countries.

\section{The way forward}

A worldwide approach is needed to tackle the global disparities in the health workforce. Innovative measures are needed to attract more trainees and to improve health worker retention in source countries. We need to tackle professional isolation, and to improve training and career prospects within source countries; these are some of the key factors currently driving the emigration of mental health professionals (Gureje et al, 2009). Such strategies should include providing financial and other incentives to stay. Institutional capacitybuilding that promotes career development should be fostered, with commensurate opportunities to receive and provide mentorship, and improvements in workplace conditions.

\section{References}

Aluttis, C., Bishaw, T. \& Frank, M. W. (2014) The workforce for health in a globalized context - global shortages and international migration. Global Health Action, 7. doi: http://dx.doi.org/10.3402/ gha.v7.23611.

Bidwell, P., Humphries, N., Dicker, P., et al (2013) The national and international implications of a decade of doctor migration in the Irish context. Health Policy, 110, 29-38.

Blacklock, C., Heneghan, C., Mant, D., et al (2012) Effect of UK policy on medical migration: a time series analysis of physician registration data. Human Resources for Health, 10, 35.

Goldberg, D. (2004) The NHS International Fellowship Scheme in Psychiatry: reply to Khan. Psychiatric Bulletin, 28, 433-434.

Gureje, O., Hollins, S., Botbol, M., et al (2009) Report of the WPA Task Force on Brain Drain. World Psychiatry, 8, 115-118.

Jenkins, R., Kydd, R., Mullen, P., et al (2010) International migration of doctors, and its impact on availability of psychiatrists in low income countries. PLOS One, 5(2), e9049. doi: http://dx.plos. org/10.1371/journal.pone.0009049.

Kakuma, R., Minas, H., Van Ginneken, N., et al (2011) Human resources for mental health care: current situation and strategies for action. Lancet, 378, 1654-1663.

Mills, E. J., Kanters, S., Hagopian, A., et al (2011) The financial cost of doctors emigrating from sub-Saharan Africa: human capital analysis. BMJ, 343, d7031.

Ndetei, D. M., Karim, S. \& Mubbashar, M. (2004) Recruitment of consultant psychiatrists from low- and middle-income countries. International Psychiatry, issue 6, 15-18.

Siyam, A. \& Poz, M. R. D. (eds) (2014) Migration of Health Workers: The WHO Code of Practice and the Global Economic Crisis. World Health Organization.

Tankwanchi, A. B. S., Özden, Ç. \& Vermund, S. H. (2013) Physician emigration from sub-Saharan Africa to the United States: analysis of the 2011 AMA physician masterfile. PLoS Medicine, 10, e1001513.

World Health Organization (2006) The World Health Report 2006 Working Together For Health. WHO. Available at http://www.who.int/ whr/2006/whr06_en.pdf (accessed June 2016).

World Health Organization (2010) WHO Global Code of Practice on the International Recruitment of Health Personnel. WHO Available at http://apps.who.int/gb/ebwha/pdf_files/WHA63/A63_R16-en.pdf (accessed June 2016). 